\title{
CHEMICAL CHARACTERIZATION OF RECENT AND BURIED WOODS BY ANALYTICAL PYROLYSIS
}

\section{COMPARISON OF PYROLYSIS DATA WITH ${ }^{13} \mathrm{C}$ NMR AND WET CHEMICAL DATA}

\author{
C. SAIZ-JIMENEZ *
}

Instituto de Recursos Naturales y Agrobiologia, C.S.I.C., Apartado 1052, Sevilla (Spain)

\section{J.J. BOON}

FOM Institute AMOLF, Kruislaan 407, 1098 SJ Amsterdam (The Netherlands)

\section{J.I. HEDGES}

School of Oceanography, WB-10, University of Washington, Seattle, WA 98195 (U.S.A.)

\section{J.K.C. HESSELS and J.W. DE LEEUW}

Delft University of Technology, Department of Chemistry and Chemical Engineering, Organic Geochemistry Unit, de Vries van Heystplantsoen 2, 2628 RZ Delft (The Netherlands)

\begin{abstract}
In a previous study, selective degradation of carbohydrates versus lignin in buried woods was demonstrated by non-destructive spectroscopy $\left({ }^{13} \mathrm{C} N \mathrm{NM}\right)$ and destructive wet chemical methods (acid hydrolysis and alkaline $\mathrm{CuO}$ oxidation). In this paper, spruce, alder and oak woods deposited in coastal sediments and their recent equivalents are characterized by pyrolysis-mass spectrometry and pyrolysis-gas chromatography-mass spectrometry. Pyrolysis data, wet chemical degradation and NMR data are in good agreement, indicating that flash pyrolysis methods are useful for fast detailed characterization of this type of organic matter.
\end{abstract}

Biomass; gas chromatography; lignin; mass spectrometry; polysaccharides; pyrolysis; wood.

\section{INTRODUCTION}

Woody tissues are the most abundant biomass components in terrestrial environments and important contributors to sedimentary and soil organic 
matter. Aerobic degradation of wood is slow because lignin is a poor substrate for microorganisms and decreases the decomposition rate of associated polysaccharides. Lignins are relatively slowly biodegraded in soils by certain fungi and bacteria, and partly degraded lignins and lignin derived phenols may contribute to the formation of humus [1]. The absence of significant wood decomposition under anaerobic conditions is a consequence of the requirement of oxygen for microbial degradation. In anaerobic wetlands and in sediments of marine and freshwater environments, woody materials are better preserved and bacteria are thought to be the major agents of wood degradation with polysaccharides being the dominant nutrient source [2].

In a previous study [3] the selective degradation of carbohydrate versus lignin in buried wood samples was demonstrated by non-destructive spectroscopy $\left({ }^{13} \mathrm{C} N M R\right)$ and destructive wet chemical techniques (acid hydrolysis and alkaline $\mathrm{CuO}$ oxidation). In the present study, the same samples are characterized by pyrolysis-mass spectrometry (Py-MS) and pyrolysis-gas chromatography-mass spectrometry (Py-GC-MS). A comparison is made between buried samples of spruce, alder and oak wood from coastal sediments with their recent living equivalents. Pyrolysis data are discussed versus chemical degradation and NMR data in order to determine the feasibility of pyrolysis methods to study the chemical structure of buried woods.

\section{EXPERIMENTAL}

\section{Samples}

Buried spruce (Picea sitchensis) and red alder (Alnus rubra) wood samples were taken $10 \mathrm{~cm}$ beneath the bark from large logs $(0.5 \mathrm{~m}$ diameter) excavated about $6 \mathrm{~m}$ apart in a silty clay horizon along the bank of the Hoko river (near the Strait of Juan de Fuca, Washington State, U.S.A.). The deposit is contemporaneous with a 2500 year old archeological site. Buried white oak (Quercus spp.) wood was obtained at a sedirnent depth of $100 \mathrm{~m}$ in a drill hole on the continental slope of the Gulf of Mexico off the coast of Louisiana and is likely to be over 25,000 years old. Recent equivalents of the three buried woods were taken from trunk wood sections. Further details on the samples have been given elsewhere [3].

\section{Curie-point pyrolysis methods}

Three Curie-point pyrolysis methods were applied. Curie-point Py-MS using the FOMautopyms was used for fingerprinting analysis of the wood pyrolysates. A recent description of the method for analysis of coal and related materials is given by Tromp et al. [4]. 
The mass range of the mass spectrometer used in this study was $m / z$ 20-220. The pyrolysis chamber and the expansion chamber were heated to 160 and $200^{\circ} \mathrm{C}$, respectively. The Curie-point temperature of the ferromagnetic wires was $610^{\circ} \mathrm{C}$. Samples were taken from suspensions in water.

Py-GC was performed in a reactor described by Van de Meent et al. [5]. The pyrolysis unit was mounted in the injection block of a Packard Becker 419 gas chromatograph or on a Varian 3700 in the case of the Py-GC-MS system. The pyrolysates were separated on a $30-\mathrm{m}$ fused silica column (I.D. $0.26 \mathrm{~mm}$ ) coated with DB-1701 (film thickness $0.25 \mu \mathrm{m}$ ). The GC oven was programmed from 0 to $300^{\circ} \mathrm{C}$ at a rate of $3^{\circ} \mathrm{C} / \mathrm{min}$. GC-MS was performed with a MAT 44 quadrupole mass spectrometer operated in the electron impact mode at $80 \mathrm{eV}$.

\section{Multivariate analysis}

Discriminant analysis was performed on the Py-MS data file, which consisted of six categories (samples) in quadruplicate. A modified ARTHUR package, specially adapted to accept Py-MS data, was used for this procedure [6]. The output consists of plots or maps which show the relative difference in composition of the samples. The variables which cause the discrimination are given in so-called discriminant functions.

\section{RESULTS AND DISCUSSION}

\section{Wet chemical studies}

The analyses of neutral sugars and lignin-derived phenols indicated that at least 90 and $98 \%$ of the initial total polysaccharides in buried alder and oak woods, respectively, have been degraded along with 15-25\% of the lignin [3]. The buried spruce was almost unaltered. The observation that softwood is more resistant to decomposition than hardwood is in agreement with previous studies [7].

\section{${ }^{13}$ C NMR}

${ }^{13} \mathrm{C}$ NMR data of these samples have been discussed elsewhere in detail [3]. The major results are summarized hereafter. The spectra of the recent woods and the buried spruce wood are dominated by resonances in the 60-110 ppm region assignable to $\alpha$-cellulose and hemicellulose. In contrast, resonances corresponding to lignin strongly predominate in the spectra of the two buried hardwood. The spectra resemble those obtained by Hatcher et al. [8] for modern spruce and a 10,000 year old buried spruce wood, which in this case has suffered selective polysaccharide degradation. 
Pyrolysis-mass spectra are fingerprints of the pyrolysates evolved from complex organic matter samples. Examples for wood and wood polymers have been shown by Windig et al. [9]. Most of the mass spectrometry information on the polysaccharide fraction in wood is present in the mass range $m / z 20-126$, whereas mass peaks for the lignins plot in the range $m / z$ 110-210. Recent changes in the pyrolysis chamber of the FOMautopyms have improved the transmission of higher molecular weight materials which results in a more complete picture of the lignin pyrolysate compared to previous data by Meuzelaar et al. [10]. The chemical significance of the mass peaks of polysaccharides and lignin in low-voltage pyrolysis spectra has been studied with Py-GC-MS using photoionisation at $11.8 \mathrm{eV}[11,12]$. Although many mass peaks are in fact impure, some tentative conclusions may be drawn in the case of complex pyrolysates such as those of woods.

Py-mass spectra of recent and buried soft (spruce) and hard (oak) wood samples are shown in Figs. 1-4. It is immediately evident that major changes in the ratio of polysaccharides to lignin have taken place in the buried oak sample. These effects are not evident in the spruce sample, although a change in the composition of the polysaccharide fraction is indicated by the decrease in the relative intensity of the mass peaks in the $m / z$ range $30-120$. The relative pure mass peak $m / z 114$, abundant in both pyrolysates, is typical of xylans. The ratios of the abundant mass peaks $\mathrm{m} / \mathrm{z}$ 57, 60 and 73 in the modern oak Py-mass spectrum (Fig. 3) resemble the distribution in levoglucosan [13], a pyrolysis product of cellulose.

Lignin appears to have undergone minor structural changes. The spectrum of spruce shows mass peaks indicative of a guaiacyl lignin with $\mathrm{m} / \mathrm{z}$

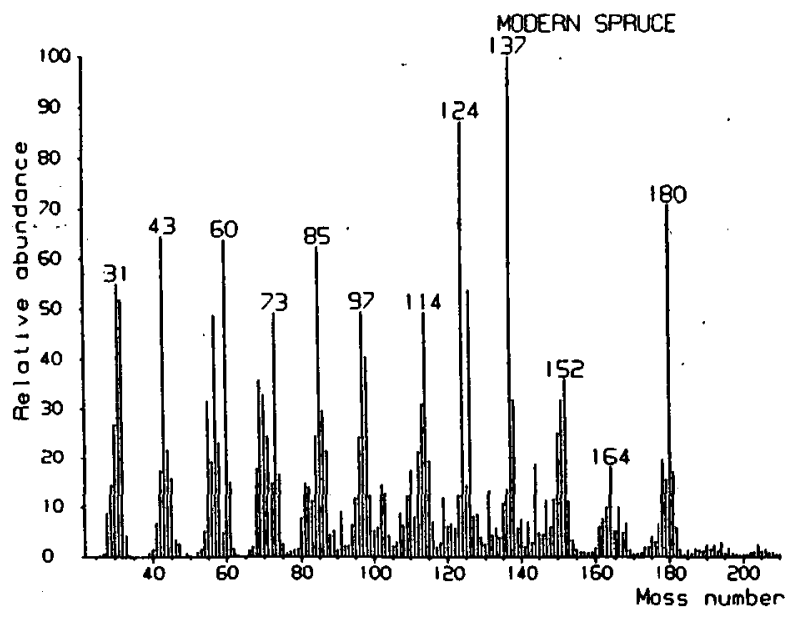

Fig. 1. Pyrolysis-mass spectrum of recent spruce sample. 


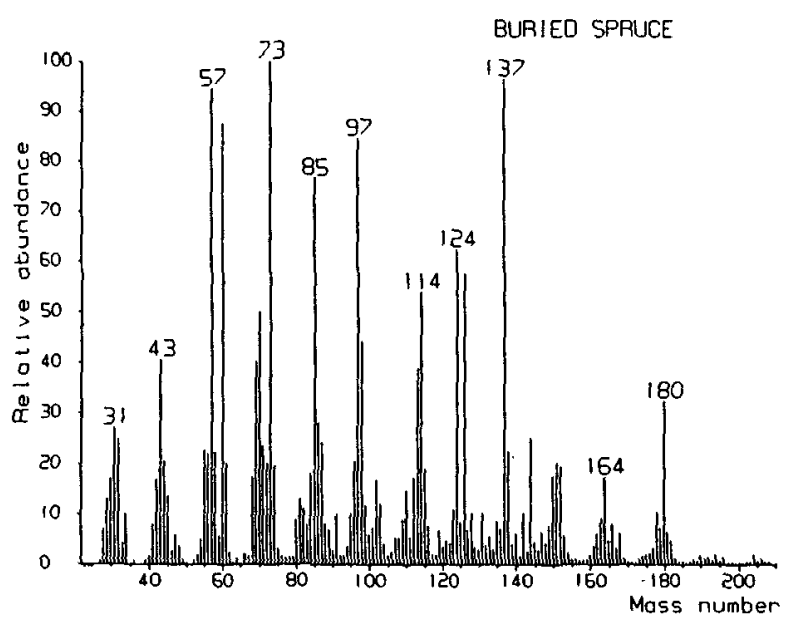

Fig. 2. Pyrolysis-mass spectrum of buried spruce șample.

$180,178,166,164,152,137$ (a fragment ion peak) and 124. Oak lignin is a mixed guaiacyl-syringyl lignin in which $m / z 210,208,196,194,182,167$ (a fragment ion peak) and 154 are indicative of the syringyl part of the macromolecule. The Py-MS profiles of the buried woods do not show any major changes in the ratios of these peaks, although the spectra of the buried hard woods show higher relative abundances for $m / z 124,164,194$ and a lower intensity of $m / z 210$.

Fig. 5 displays a map of the scores of the samples on the first and second discriminant functions, which show their relative difference in composition. The euclidian distance of the sample points is a measure of the difference in

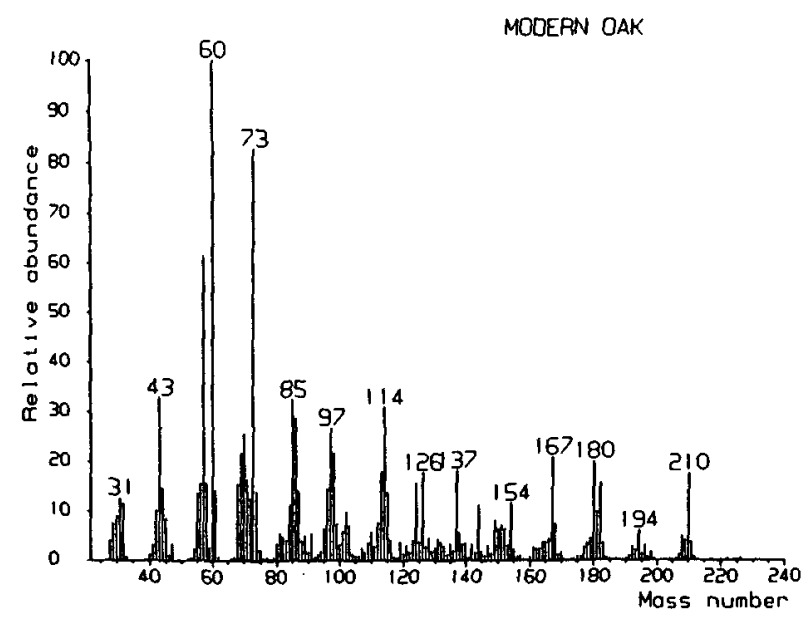

Fig. 3. Pyrolysis-mass spectrum of recent oak sample. 


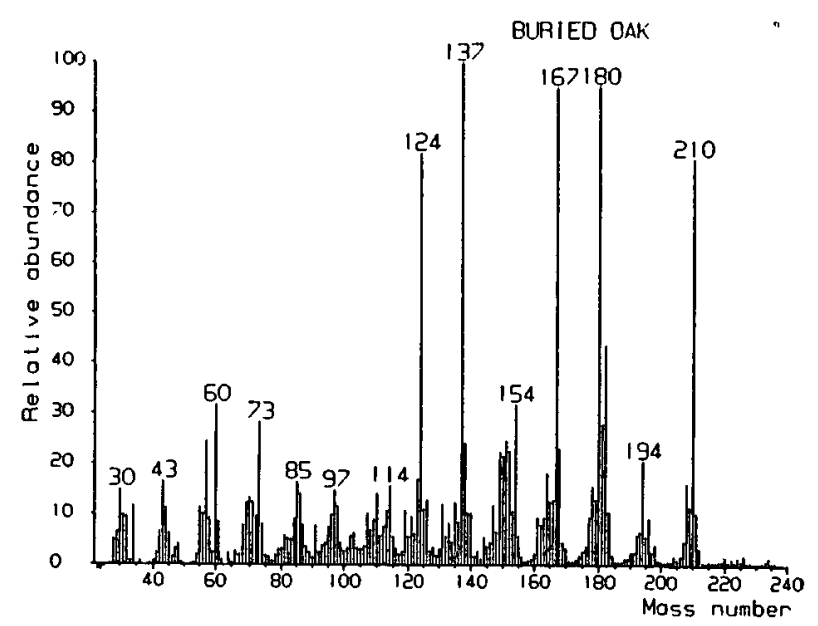

Fig. 4. Pyrolysis-mass spectrum of buried oak sample.

their Py-mass spectra. About $85 \%$ of the characteristic variance between the samples is explained by this $D_{1} D_{2}$ map. The reconstructed mass spectra of the first discriminant function (Fig. 6) shows that this axis of variance concerns the ratio of polysaccharides (mass peaks in D1+) and lignins (mass peaks in D1 - ). All recent woods plot high on D1 + (Fig. 6), whereas the buried woods, with the exception of spruce, plot towards lower polysaccharide and higher lignin markers $(\mathrm{D} 1-)$. The second axis of variance

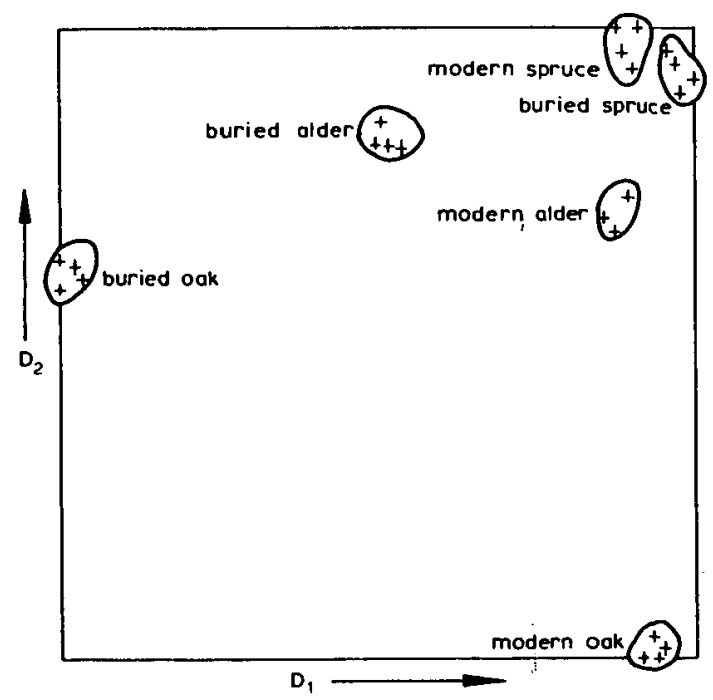

Fig. 5. $D_{1} D_{2}$ map with the scores of the samples. 

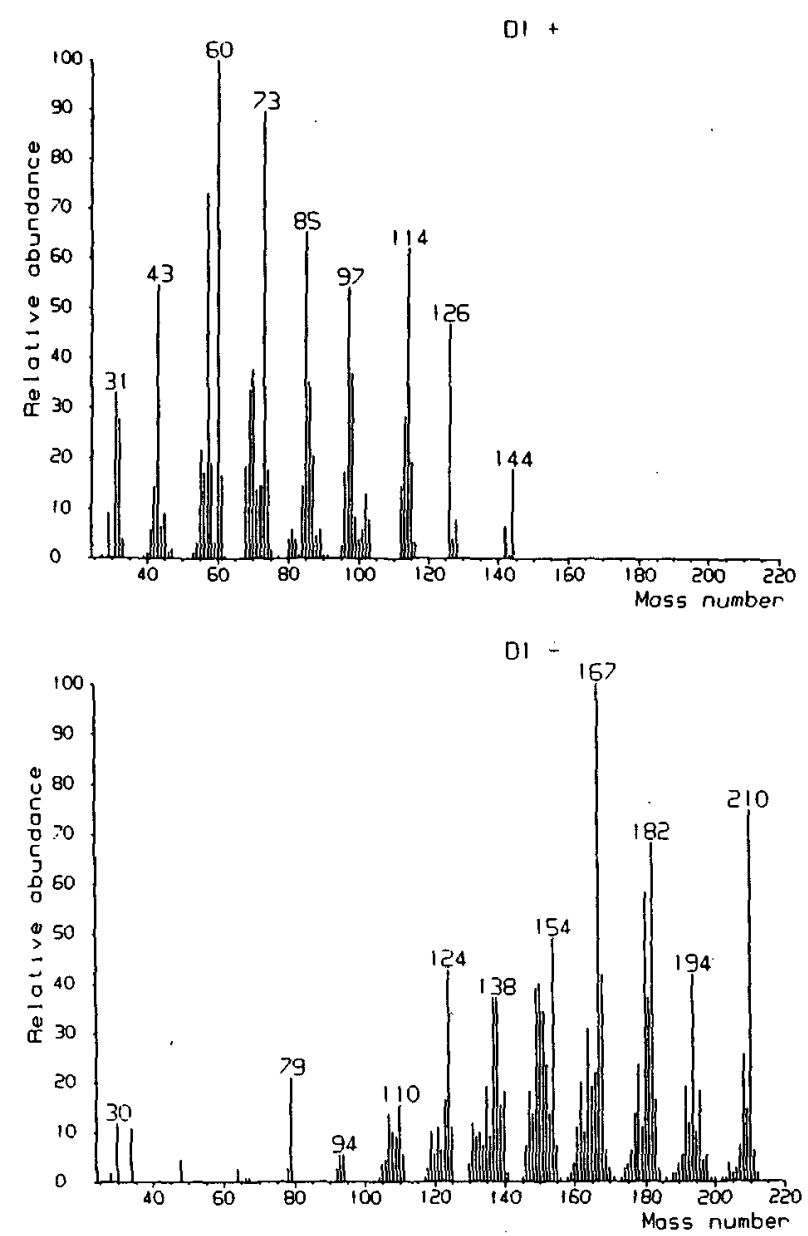

Fig. 6. Content of the first discriminant function. Upper trace, D1 + ; lower trace, DI - .

concerns the nature of the lignin, i.e. the ratio between guaiacyl and syringyl markers, which is evident from the reconstructed mass spectra of the second discriminant function (Fig. 7). The D2 + spectrum is indicative of guaiacyl units $(m / z 180,178,152,137,124)$. The spectrum of $D 2$ - shows mass peaks for syringyl units $(m / z 210,194,182,167,154)$ as well as peaks for levoglucosan $(m / z 57.60,73)$.

Recent spruce and buried spruce score highest on $D 2+$ because they contain only guaiacyl lignin. The modern oak scores highest on the syringyl side of D2. Recent and buried alder take intermediate positions, partly because of their guaiacyl/syringyl ratio and also because of the change in polysaccharide/lignin ratio in the fossil sample. The two hardwoods have undergone the strongest degradation of their woody tissues, as the euclidean 

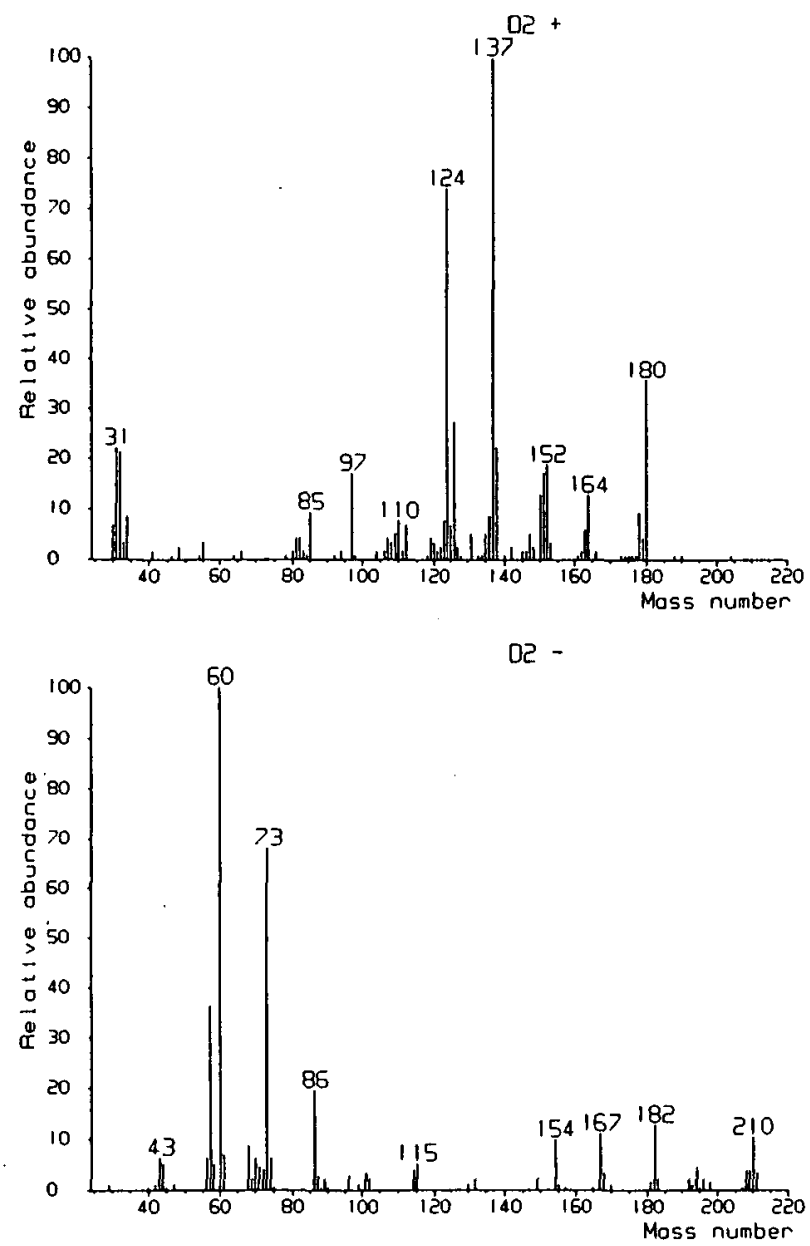

Fig. 7. Content of the second discriminant function. Upper trace, D2+; lower trace, D2-.

distance between recent wood and fossil material is substantial. The buried spruce sample plots close to the modern undecomposed equivalent, which means that the buried spruce sample is only slightly decomposed compared to the other samples. It is likely that the high levoglucosan evolution from the oak sample is a special characteristic, which may not be representative for all oak secondary xylem. These pyrolysis results are in full agreement with the previously obtained spectral and chemical degradative analyses.

Pyrolysis-gas chromatography-mass spectrometry

Py-GC traces of wood samples show the complexity of the pyrolysis product mixtures (Figs. 8-10). The identities of major and significant 

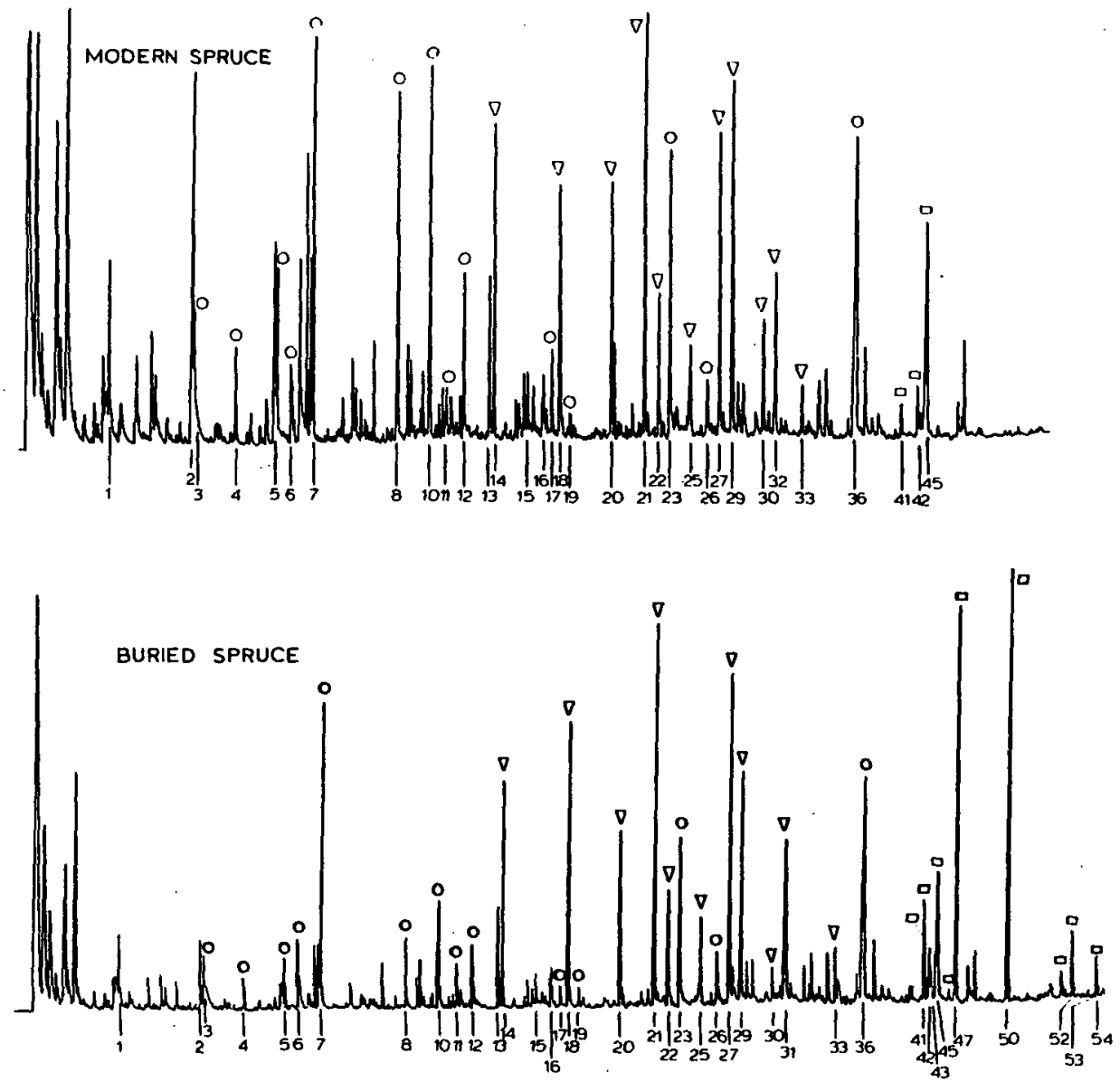

Fig. 8. Pyrolysis-gas chromatography trace of recent spruce sample (upper trace) and buried spruce sample (lower trace). The numbers correspond with the numbers in Table 1. $O$ : Polysaccharide pyrolysis products; $\nabla$ : guaiacyl lignin pyrolysis products; $\Delta:$ syringyl pyrolysis products; $\square$ : resin compounds.

compounds are given in Table 1 . Recent woods yield high amounts of polysaccharide pyrolysis products such as 2-furaldehyde (7), $\alpha$-angelicalactone (8), 5-methylfuraldehyde (10), 4-hydroxy-5,6-dihydro-2H-pyran-2-one (11) and levoglucosan (36). These compounds are yielded in drastically reduced amounts from the buried hardwoods, but much less so from the buried spruce wood. In comparison to the native woods the pyrolysis products of the guaiacyl lignin and syringyl lignin are relatively increased in the alder and oak buried woods, while in the spruce this increase is less significant.

The most prominent guaiacyl lignin pyrolysis products are methylguaiacol (18), vinylguaiacol (21), trans-isoeugenol (27) and vanillin (29). Among the 

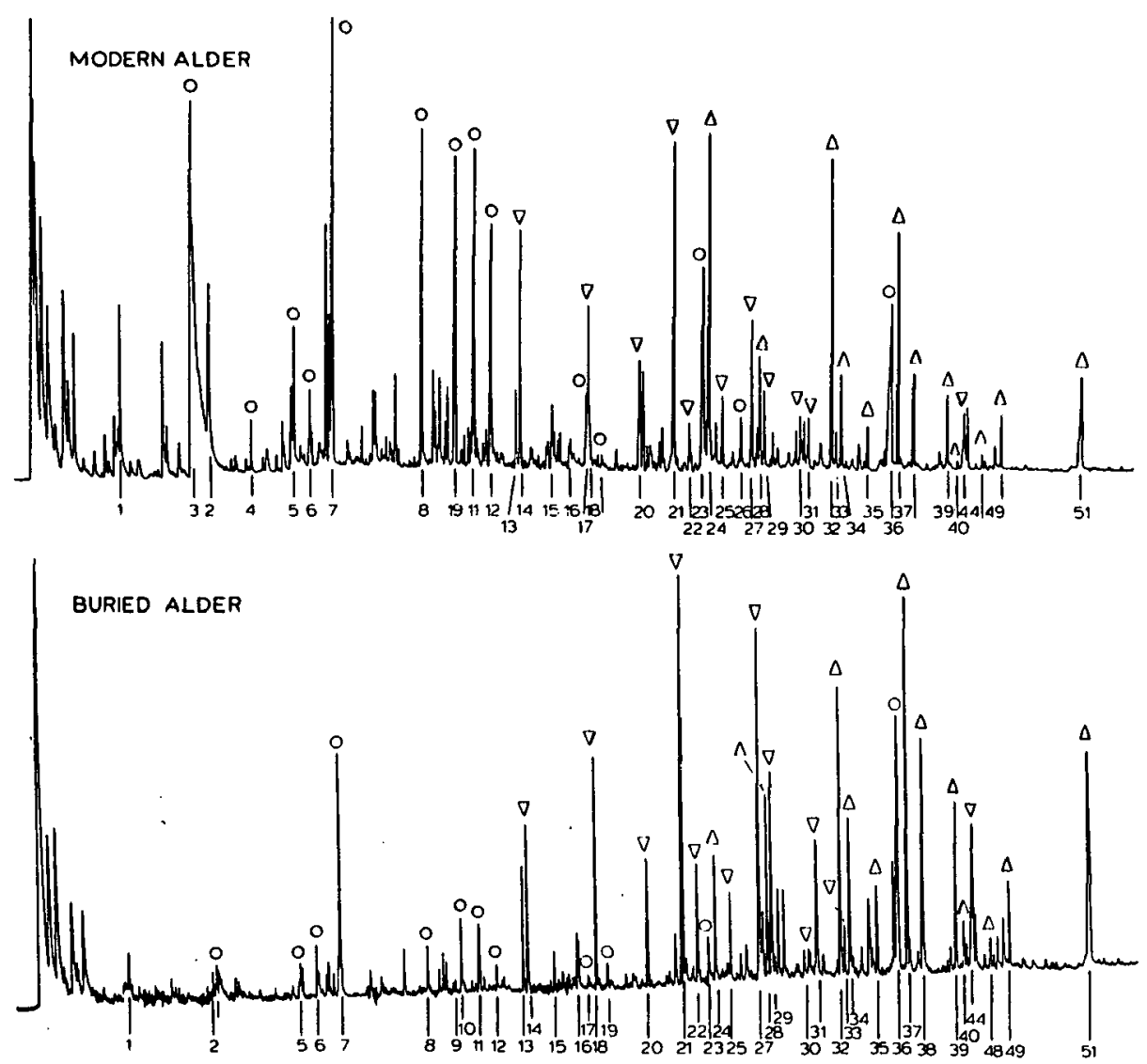

Fig. 9. Pyrolysis-gas chromatography trace of recent alder sample (upper trace) and buried alder sample (lower trace). See legend of Fig. 8 for significance of numbers and symbols.

syringyl lignin compounds, 2,6-dimethoxyphenol (24), vinyl-2,6-dimethoxyphenol (32), trans-propenyl-2,6-dimethoxyphenol (37) and syringaldehyde (38) predominate.

The recent and buried spruce woods are, however, different with respect to another type of compound, viz. resins. The buried spruce contained relatively large amounts of abietic acid derivatives, such as dehydroabietin (47) and nor-simonellite (50). This difference in resin content between the recent and the buried wood samples was not observed by NMR and chemical degradation [3]. Although not checked it is believed on the basis of previous studies [14] that the resin compounds are mainly present as such and simply evaporate during the rapid heating of the wire. The relatively different amounts of resin compounds are probably due to heterogeneity of the samples and not indicative of any relative enrichment of resin compounds upon burial. 

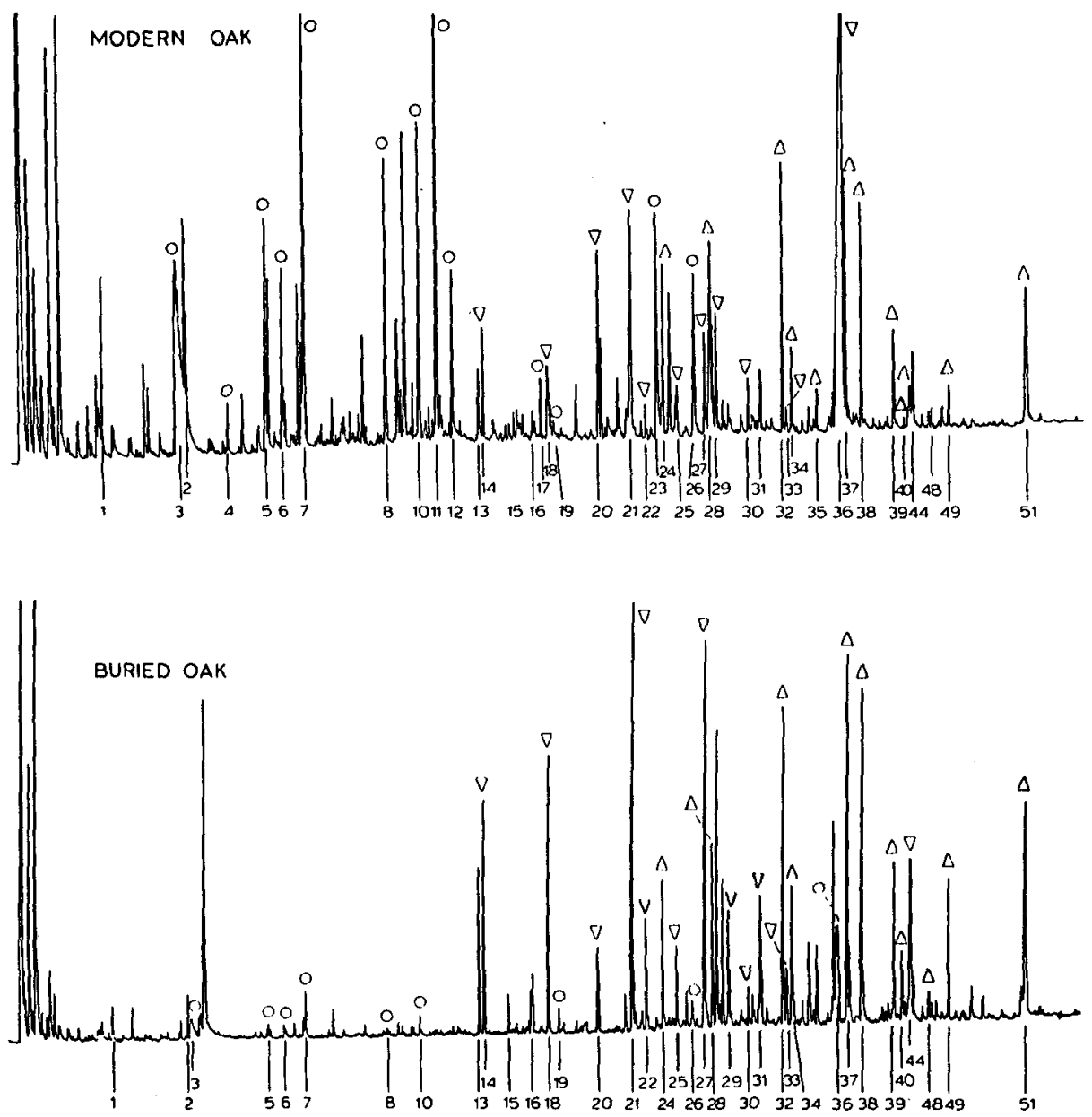

Fig. 10. Pyrolysis-gas chromatography trace of recent oak sample (upper trace) and buried oak sample (lower trace). See legend of Fig. 8 for significance of numbers and symbols.

Guaiacyl lignin $(G)$ versus syringyl lignin (S) ratios have been calculated from the intensities of identified pyrolysis products (Table 2). Percentages of identified polysaccharide, lignin and resin pyrolysis and evaporation products were also calculated (Table 3). It is clear from the $G / S$ ratios that during burial a selective loss of syringyl units occurs. Furthermore, the comparison of the percentages of different components indicates that polysaccharides decrease during burial in all woods: less in the spruce, but significantly in the oak sample. Guaiacyl lignin pyrolysis products remain almost constant in the buried spruce. The Py-GC-MS data thus are in good agreement with the Py-MS and discriminant analysis data. 
The study of chemical changes in woods after burial can be accomplished by wet chemical, spectroscopic or analytical pyrolysis methods. As already mentioned these three different approaches are in very good agreement with each other. Nevertheless there are a number of aspects to consider when comparing these different and partly complementary techniques.

Wet chemical degradations are lengthy, tedious, and of ten involve derivatization of reaction mixtures before analysis. Further, the hydrolysis and degradation reactions applied are far from complete, so the figures obtained are underestimates. It has been reported that $\mathrm{CuO}$ oxidation of guaiacyl lignin only yields $30 \%(w / w)$ of phenols [3]. These approaches do give, however, detailed information on the individual structural moieties present in the macromolecular assemblages.

\section{TABLE 1}

Compounds identified in the pyrolysates of the recent and buried wood samples

\begin{tabular}{rlrl}
\hline No. & Compound & No. & Compound \\
\hline 1 & Benzene & 28 & Methyl-2,6-dimethoxyphenol \\
2 & Toluene & 29 & Vanillin \\
3 & Acetic acid & 30 & Homovanillin \\
4 & 2-Methylfuran & 31 & Acetoguaiacone \\
5 & Dihydropyran & 32 & Vinyl-2,6-dimethoxyphenol \\
6 & 3-Furaldehyde & 33 & Guaiacylpropan-2-one \\
7 & 2-Furaldehyde & 34 & Allyl-2,6-dimethoxyphenol \\
8 & a-Angelicalactone & 35 & cis-Propenyl-2,6-dimethoxyphenol \\
9 & a-Methylbenzylalcohol & 36 & Levoglucosane \\
10 & 5-Methylfuraldehyde & 37 & trans-Propenyl-2,6-dimethoxyphenol \\
11 & 4-Hydroxy-5,6-dihydro-2H-pyran-2-one & 38 & Syringaldehyde \\
12 & 2-Hydroxy-3-methyl-2-cyclopenten-2-one & 39 & (2.6-Dimethoxyphenyl)-ethanal \\
13 & Phenol & 40 & (2,6-Dimethoxyphenyl)-ethanone \\
14 & Guaiacol & 41 & 19-nor-Dehydroabietane \\
15 & o-Cresol & 42 & nor-Abietane \\
16 & p-Cresol & 43 & Isomer of 41 \\
17 & Levoglucosenone & 44 & Coniferaldehyde \\
18 & Methylguaiacol & 45 & Isomer of 41 \\
19 & 3,5-Dihydroxy-2-methyl-4H-pyran-4-one & 46 & 19-nor-Abieta-4(18)8,11,13-tetraene? \\
20 & Ethylguaiacol & 47 & Dehydroabietin \\
21 & Vinylguaiacol & 48 & (2,6-Dimethoxyphenyl)-propanone \\
22 & Eugenol & 49 & (2,6-Dimethoxyphenyl)-propanedione \\
23 & 5-(Hydroxymethyl)-2-furaldehyde & 50 & nor-Simonellite \\
24 & 2,6-Dimethoxyphenol & 51 & Sinapaldehyde \\
25 & cis-Isoeugenol & 52 & Retene \\
26 & 1,4-Dideoxy-D-glycerohex-1-enopyranos- & 53 & Dehydroabietane \\
& 3-ulose & 54 & Simonellite \\
27 & trans-Isoeugenol & & \\
\hline
\end{tabular}


TABLE 2

Ratios of guaiacyl and syringyl pyrolysis products in the pyrolysates of the hardwood samples

\begin{tabular}{|c|c|c|c|c|c|c|}
\hline \multirow[t]{2}{*}{$\bar{R}$} & \multicolumn{4}{|l|}{$\mathrm{G} / \mathrm{S}$} & \multirow[t]{2}{*}{ Guaiacyl unit } & \multirow[t]{2}{*}{ Syringyl unit } \\
\hline & $\begin{array}{l}\text { Modern } \\
\text { alder }\end{array}$ & $\begin{array}{l}\text { Buried } \\
\text { alder }\end{array}$ & $\begin{array}{l}\text { Modern } \\
\text { oak }\end{array}$ & $\begin{array}{l}\text { Buried } \\
\text { oak }\end{array}$ & & \\
\hline$-\mathrm{H}$ & 0.71 & 1.28 & 0.97 & 1.55 & & \\
\hline$-\mathrm{CH}_{3}$ & 1.43 & 1.29 & 0.69 & 1.48 & & \\
\hline$-\mathrm{CH}=\mathrm{CH}_{2}$ & 1.06 & 1.38 & 0.84 & 1.41 & & \\
\hline$-\mathrm{CH}=\mathrm{CH}-\mathrm{CH}_{3}$ & 0.63 & 0.95 & 0.40 & 1.06 & & \\
\hline$-\mathrm{CHO}$ & 0.81 & 0.87 & 0.51 & 0.89 & . & \\
\hline$-\mathrm{CO}-\mathrm{CH}_{3}$ & 0.48 & 0.80 & 0.54 & 0.25 & & \\
\hline$-\mathrm{CH}=\mathrm{CH}-\mathrm{CHO}$ & 0.61 & 0.68 & 0.30 & 0.85 & $\mathrm{OH}$ & $\mathrm{OH}$ \\
\hline$\Sigma$ & 0.83 & 1.03 & 0.62 & 1.08 & & \\
\hline
\end{tabular}

The solid-state ${ }^{13} \mathrm{C}$ NMR technique offers limited resolution of specific changes on the molecular level that might characterize wood degradation [3].

On the other hand the advantage of the ${ }^{13} \mathrm{C}$ NMR analysis is that the method is relatively speaking the most quantitative one.

Analytical pyrolysis methods are non-selective, can be applied to comparatively small samples (microgram level) in a highly reproducible way, and provide data at the molecular level of polysaccharides, lignins and resins without any pretreatment of samples. The application of multivariate analysis of Py-MS data to classify native and decomposed woods opens the possibility of evaluating large series of samples.

It has been suggested that wood characteristics have been preserved with relatively little morphological changes in some brown coals because of the conifer resins that protect the wood from extensive alteration [8].. The presence of diterpenoid compounds derived from abietic acid in the buried spruce wood supports this explanation. Although it was concluded from wet chemical analyses that the polysaccharide content in the buried wood is

TABLE 3

Percentages of identified polysaccharide and lignin pyrolysis products

\begin{tabular}{llllc}
\hline & Polysaccharide & $\begin{array}{l}\text { Guaiacyl } \\
\text { lignin }\end{array}$ & $\begin{array}{l}\text { Syringyl } \\
\text { lignin }\end{array}$ & $\begin{array}{l}\text { Resin } \\
(\%) \star\end{array}$ \\
\hline Modern spruce & 49.3 & 50.7 & - & 5.9 \\
Buried spruce & 37.6 & 62.4 & - & 26.0 \\
Modern alder & 48.3 & 25.7 & 26.9 & - \\
Buried alder & 19.4 & 41.6 & 39.0 & - \\
Modern oak & 55.8 & 18.7 & 25.5 & - \\
Buried oak & 6.3 & 50.3 & 43.4 & - \\
\hline
\end{tabular}

- Percentage of resin compounds with regard to polysaccharide + lignin pyrolysis products. 
unaltered [3], the Py-MS and Py-GC-MS data indicate that some polysaccharide pyrolysis products decrease significantly and others do not. It appears probable that modifications in polysaccharide structure, possibly by changes in intermolecular bonding, are the reason. Further studies are however required to investigate this hypothesis.

An interesting fact is the absence in the buried wood samples of significant amounts of oxidized phenols (e.g. vanillic and syringic acids). These compounds reflect the aerobic fungal degradation of lignins and woods [15]. Because the degradation of woods in aerobic environments is an oxidative process requiring oxygen, the low amount of oxidized phenols in the buried wood samples might reflect an anoxic burial history.

\section{ACKNOWLEDGEMENT}

This research was funded by the C.S.I.C. and C.A.I.C.Y.T., Spain (Project No. 781) and the Dutch Foundation for Fundamental Research on Matter (FOM).

\section{REFERENCES}

1 C. Saiz-Jimenez and J.W. de Leeuw, J. Anal. Appl. Pyrolysis, 9 (1986) 99.

2 R. Benner, S.Y. Newell, A.E. Maccobin and R.E. Hodson, Appl. Environm. Microbiol., 48 (1984) 36.

3 J.I. Hedges, G.L. Cowie, J.R. Ertel, R.J. Barbour and P.G. Hatcher, Geochim. Cosmochim. Acta, 49 (1985) 701.

4 P.J.J. Tromp, J.A. Moulijn and J.J. Boon, Fuel, 65 (1986) 960.

5 D. van de Meent, S.C. Brown, R.P. Philp and B.R.T. Simoneit, Geochim. Cosmochim. Acta, 44 (1980) 999.

6 J.J. Boon, A. Tom, B. Brandt, G.B. Eijkel, P.G. Kistemaker, F.J.W. Notten and F.H.M. Mikx, Anal. Chim. Acta, 163 (1984) 193.

7 D.D. Nicholas, Wood Determination and its Prevention by Preservative Treatments, Vol. 1, Syracuse University Press, Syracuse, NY, 1970.

8 P.G. Hatcher, I.A. Breger and W.L. Earl, Org. Geochem., 3 (1981) 49.

9 W. Windig, H.L.C. Meuzelaar, F. Shafizadeh and R.G. Kelsey, J. Anal. Appl. Pyrolysis, 6 (1984) 233.

10 H.L.C. Meuzelaar, J. Haverkamp and F.D. Hileman, Pyrolysis Mass Spectrometry of Recent and Fossil Biomaterials, Elsevier, Amsterdam, 1982.

11 W. Genuit, Ph.D. Thesis, Amsterdam, 1986.

12 W. Genuit, J.J. Boon and O. Faix, Anal. Chem., 59 (1987) 508.

13 W. Genuit and J.J. Boon, J. Anal. Appl. Pyrolysis, 8 (1985) 25.

14 M. Nip, J.W. de Leeuw, P.A. Schenck, H.L.C. Meuzelaar, S.A. Stout, P.H. Given and J.J. Boon, J. Anal. Appl. Pyrolysis, 8 (1985) 221.

15 C. Saiz-Jimenez and J.W. de Leeuw, Org. Geoçhem., 6 (1984) 417. 